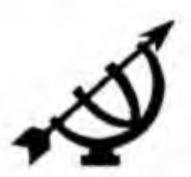

\title{
Re-authoring marital partners' stories The aid of sculpting and the use of small objects as "co-therapists"
}

\author{
C.A. Venter \\ Department of Psychology \\ Potchefstroom University for CHE \\ POTCHEFSTROOM \\ E-mail: psgcav@puknet.puk.ac.za
}

Abstract

Re-authoring marital partners' stories. The aid of sculpting and the use of small objects as "co-therapists"

\begin{abstract}
As a result of the high divorce rate and the traumatic and far-reaching effects these phenomena have on adults and children, psychologists should constantly aim to develop effective ways of marriage counselling and therapy. The aim of this article is to introduce one approach to marriage therapy that has been developed by the author of this article. Within this approach to marriage therapy the therapist employs the assistance of a number of figurines and objects utilized as "co-therapists" during the therapy sessions to represent the marriage partners' relationship. During this process the emphasis falls on the close proximity or distance (i.e. intimacy or lack of it) between the marniage partners, and the difference in height (i.e. power relations) which exists between the partners. Experience has indicated that this approach is a powerful diagnostic and therapeutic technique. In this article a theoretical grounding for this technique, methods of presentation and the rationale behind the technique are discussed. Suggestions for further research about the technique, as well as for the development of it are also given.
\end{abstract}

\section{Introduction}

The divorce rate in South Africa is alarmingly high. Statistics of 1996 indicate that 146732 marriages were solemmized, 32775 divorces were officially granted, and 41971 minors were involved in these divorces (Statistics SA, 1998). As a result of the traumatic and far-reaching effects that divorce has/can have on both adults and children (cf. Everett \& Volgy, 1991; Hodges, 1991; Venter et al., 1995), and in view of the com- 
Re-authoning manital partners' stories. The aid of sculpting and the use of small objects

plex nature of marital problems and the difficulties experienced by marital partners in their attempts to solve these problems, it is essential that marital therapists should continuously attempt to develop new creative approaches (techniques) to assist marital couples in coping with their problems. Naturally such approaches (techniques) should be based on sound theoretical principles. This point of departure should be a matter of special priority for the Christian psychologist: from the Scripture it is clear that God instituted marriage as a lifelong commitment between husband and wife - a relationship in which they should show loyalty and love towards one another (De Bruyn, 1996).

Because of his own attempts and failures to assists marital couples, the author of this article has developed a simple but powerful technique to assist couples in coping with their problems. The technique that has been developed is based on the integration of the assumptions of a number of theoreticians/therapists about the marital interaction between partners, and a variety of therapeutic approaches and techniques.

\section{Theoretical foundation of the technique}

Subject-related literature indicates that a large number of theoreticians using various theoretical points of departure conceptualize the relationship between people (and also marital partners) in terms of the degree of fusion and differentiation (individuation). Stated in simplified terms, this view implies a focus on the distance that people maintain in their relationships. Examples of theoreticians sharing this view are Bowen (1976), Karpel (1976) and Sager (1981).

Bowen (as quoted by Kerr, 1981:236) proposes that in human relationship systems two natural forces exist that act to counter-balance each other, viz. a force towards individuality or autonomy, and a force towards togetherness or fusion. According to Bowen (in Kerr, 1981:236) these forces are in constant motion, with each member within the relationship monitoring the current status of the balance. A feeling of too much togetherness will trigger efforts to recover some individuality and a feeling of a limited togetherness will stimulate moves towards emotional closeness.

Karpel (1976) and Sager (1981), in their conceptualization and representation of the relationship dynamics, specifically focus on the interactional contracts which may occur between marital partners. Karpel indicates 4, and Sager 7 such kinds of relationships. Karpel (1976:7081 ), in his integration of many theoreticians'/therapists' work, proposes 4 modes of relationship, viz. unrelatedness, fusion, ambivalent fusion and dialogue. 
- Unrelatedness refers to the situation where close relationships are largely avoided.

- Fusion exists in a relationship when two minimally individuated persons form a close emotional relationship. Their dependence on one another drives them to be almost exclusively relationshiporientated. Little or no energy is devoted to the task of self-growth and individuation.

- The essence of the third relational mode, ambivalent fusion, is the conflict between progressive tendencies towards differentiation and regressive tendencies towards identification. This mode of relationship is often experienced as being caught between the fear of being totally absorbed in a fusion with another person, and the fear of being alone. Because of this kind of conflict a range of different sub-relational forms can develop as a way in which people handle this conflict, viz.

- one-partner distancing,

- alternative distancing by the partners creating cycles of fusion and unrelatedness,

- continual conflict and

- the impairment of one partner (Karpel, 1976:74-77)

- The fourth relational mode, as proposed by Karpel (1976) is dialogue. This mode represents a mature relational mode in which each person strives to respect the other person in the relationship as someone who is separate and different from the self. Consequently, the individuation of each person in the relationship operating within this relational mode will increasingly be promoted.

Sager (1981:97-103) indicates 7 interactional contracts that partners can use in a relationship to fulfil their separate goals and purposes. These contracts include the equal, the companionate, the romantic, the parallel, the rational, the parental and the childlike partner.

- The equal partner seeks a relationship on equal terms for himself and his spouse, and expects that both will have the same rights, privileges and obligations. He/she expects his/her partner to be a complete person in his/her own right, largely self-activating, but responsive to the needs of his/her mate and emotionally interdependent of him/her.

- The companionate partner wants a companion with whom to share daily living but he/she does not aspire such a close (intimate) relationship as the equal partner requires. 
Re-authoring marital partners' stories. The aid of sculpting and the use of small objects

- The romantic partner behaves as if he/she wants and expects his/her partner to be his/her soul mate and to act as one entity

- The parallel partner interacts so as to avoid an intimate sharing relationship. He/she wants the partner to respect his/her emotional distance and independence.

- The rational partner tries to establish a reasoned, logical, well-ordered relationship with his/her mate. He/she depends on his/her partner to bring spontaneity and emotional expression into their relationship.

- The essence of the dynamics of the parental partner is to control his/her partner. The parental partner sometimes assumes the role of the protective parent or he/she behaves like a punitive authoritarian parent.

- The childlike partner is the counterpart of the parental partner. In the interaction he/she aims to be cared for, protected, disciplined, guided and freed from responsibility.

It thus seems as if Sager's interactional contracts can be related to those of Bowen and Karpel.

In the first 4 partner styles as proposed by Sager (1981), the focus is on the distance/closeness that the partners have but the last two of Sager's interactional contracts (parental partner and childlike partner) allude to the differences in power that may exist in relationships. Other theoreticians, e.g. the structural family therapists, strategic family therapists and Bowen also emphasize this dimension in relationships (cf. Hanna \& Brown, 1999; Colapinto, 1991; Levant, 1984; Madanes, 1991).

In view of the above information, the hypothesis is that two basic dimensions in relationships are the proximity between marital partners and the differences in power between them. It is evident from a number of sources that these dimensions of distance and power in relationships play important roles in functional and dysfunctional relationships, and consequently these should be dealt with during therapy sessions (cf. Bartle \& Rosen, 1994; Becvar \& Becvar, 1996; Goldner, 1998; Holtzworth-Munroe \& Jacobson, 1991; Worden, 1999). It is also noticeable that Bowen and Karpel's theoretical perspectives serve as the basic points of departure for most of the above-mentioned theorists/therapists. It is also striking and remarkable that these same two dimensions (distance/proximity and status) are indicated in Scriptures as two essential dimensions in interpersonal relations (Kruger, 2000). 
The discussion of the technique itself (cf. 3 ) will indicate that a modified form of sculpting is often used during therapy sessions. This technique utilizes small objects and figurines acting as "co-therapists" to represent the relationship between marital partners. L'Abate et al. (1986) clearly indicate the advantages of this technique in their comprehensive discussion of sculpting. In short, it can be stated that the technique "... is a potent process of concretizing and exploring relationships, with the ability to condense meaning into an evocative, efficient image which is easier to store, retrieve, and relate to than equivalent verbal descriptions" (Papp quoted in L'Abate et al., 1986:166).

To some extent the therapeutic position that the therapist assumes during the session(s) agrees with that of the Milan therapists and some narrative therapists (especially Michael White, Harlene Anderson \& Goolishian, and De Shazer). Two of the strategies of the Milan School, viz. hypothesizing and curiosity are especially utilized (cf. Palazzoli et al., 1980; Cecchin, 1987). Curiosity helps the therapist to continue looking for different descriptions of and explanations for the couple's ideas, their behaviour and the explication of events in their lives. From this perspective, many hypotheses can be derived from the couple's stories. In terms of narrative therapy, the marital partners are stimulated to discover alternative stories and "new-old" stories about their relationship and not only to focus on the dominant story of their relationship (Hewson, 1991; White, 1991; White \& Epston, 1990). In terms of the work of Anderson and Goolishian (1988) the therapist should ensure that sufficient emotional space is created during the sessions, so that the marital partners can articulate the "unsaid" or the "not-yet-said", as these new/alternative perspectives are viewed as the resource for possible change during a therapy process. Within this "circle of the unexpressed" the therapist and the marital couple can co-create and co-develop new themes and new narratives (stories). In the co-creation of new stories the therapist, taking cognisance of the work of De Shazer (1991), can help couples to construct progressive narratives (i.e. new stories signalling changed insight and acting as sources for desired change in their lives). The construction of these progressive narratives are important because couples experiencing problems usually have stability and/or regressive narratives about their lives (i.e. narratives that justify that their lives are unchanging - stable - and narratives that indicate that their lives are moving away from their goals). In view of Tom Andersen's (1998) comments care is taken that the therapist and the clients use everyday language in the communication process. 
Re-authoring marital partners' stories. The aid of sculpting and the use of small objects

The position the therapist takes in during the therapy process should not assume the role of "expert", but rather the position of "I do not know". This position implies that the therapist should not present couples experiencing marital problems with general "universal truths" about the dynamics of marriage. The therapist should rather, in cooperation with the marital partners, support a number of interpretations of reality (cf. Anderson \& Goolishian, 1988; Dashti \& Wigg, 1997; White, 1995).

\section{The technique}

The application of this technique implies that the marital partners' stories are redefined and re-authored in terms of partners' closeness and power in the relationship. In this re-authoring process small objects are utilized as "co-therapists" to simulate a certain position.

The "co-therapists" used by the author of this article consist of certain ornaments and objects. The two "co-therapists" that has been used most often are an owl $(10 \mathrm{~cm}$ tall and a diameter of $9 \mathrm{~cm})$ and a wire figure $(7 \mathrm{~cm}$ tall with a diameter of $5 \mathrm{~cm}$ ) (cf. figure 1). These two "cotherapists" usually represent the two marital partners. The problem in the relationship (a particular matter or person) is sometimes represented by a small monster $(5 \mathrm{~cm}$ tall and $7 \mathrm{~cm}$ in diameter) (cf. figure 1). Children are represented by erasers of different sizes. An object often used in the representation of a situation is a notebox made of wood $(7 \mathrm{~cm} \times 7 \mathrm{~cm} \times 4$ $\mathrm{cm}$ ). Certain figures are placed on this container to indicate the differences in height. Sometimes this box is placed on its side and between two figures to indicate a definite barrier between persons.

During the session(s) the sculpting process is done on the therapist's desk. The marital partners are requested to indicate whether the sculpting is a true reflection of their respective stories. The horizontal distance between the "co-therapists" indicate the proximity between partners in the relationship (their intimacy), and the vertical differences (if indicated by the use of the notebox) indicate the differences in power.

During the discussion(s) which follow the sculpting pattern can be changed. In many cases the marital partners change the sculpting themselves by moving the "co-therapists". New themes (stories) are discovered through this process, as well as smaller nuances of wellknown stories. 


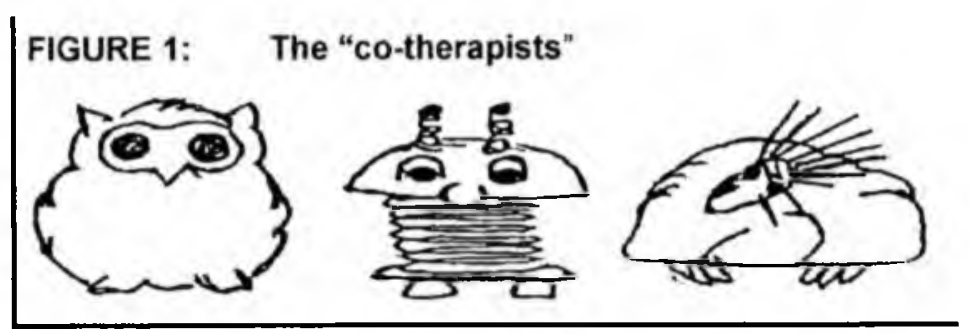

\section{Case study}

A married couple in their mid-thirties reported for therapy as the husband was uncertain as to whether he still wished to continue their unfulfilled marital relationship

At the beginning of the first session he indicated that he felt as if there were a wall between him and his wife. He also indicated that he had already wondered whether it would not be better to be divorced. As a result of his openness and obvious impatience with the situation, the therapist decided to sculpt the information provided on his desk. The husband was represented by the owl, his wife was represented by the wire figure, and the wall between them by the notebox (cf. figure 2). A number of questions were formulated and hypotheses about the situation were then deduced - for example: If the wife had also been aware of the wall between them, for how long had she been aware that this wall had existed. Further questions that could be asked, include the following: What did each of them contribute to the building of the wall? What did each of them experience in their relationship before the wall had been created? What difference did the wall make in their relationship and lives as people? What had they already tried to do to break down the wall? How did each one maintain the wall? Why did they think these attempts had failed? On the last question the husband replied that he felt that he would have to push the wall away or alternatively turn around and end the marital relationship. Many other alternative options of what he could do were then indicated to him by pointing to the sculpting on the desk, and by changing the position of the owl. These suggestions led to the generation of many new questions and hypotheses regarding the various possibilities. The following questions were considered: what would happen if he were to stand against the wall, call his wife and ask her how she experienced the wall; what would happen if he looked over the wall and asked her to help him to gradually break down the wall; etc. Upon inquiry at the end of the session, it seemed as if both partners had 
benefited from the session, and that it had been instructive to sculpt their relational problems as had been done.

During the second session the husband seemed determined to remove the wall between his wife and himself. From the ensueing discussion, it seemed as if he had been experiencing a great deal of frustration resulting from his wife's over-involvement with their children. He experienced his position as that of an outsider. The sculpting made during the first session was again arranged on the desk (cf. figure 2).

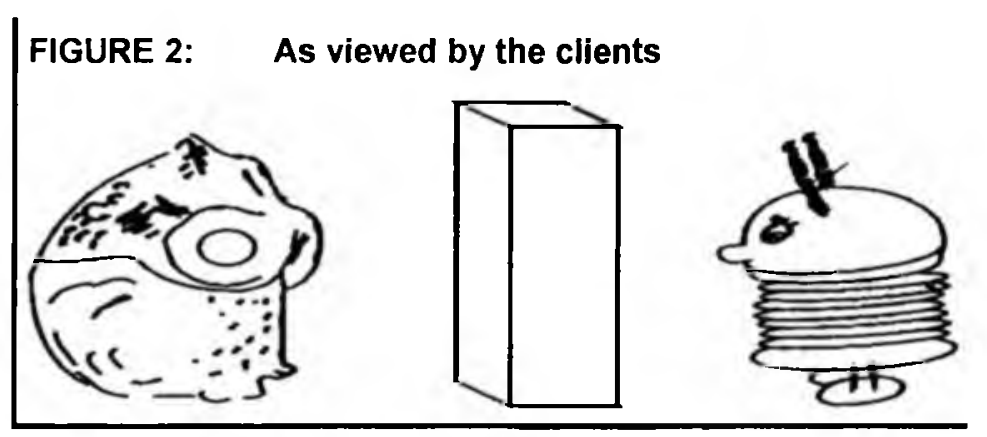

By asking a number of questions, it was then attempted to determine the positions of the two children, aged 10 and 6 years respectively, and to determine how each one fitted into the sculpting pattern. The children were represented by erasers. Initially both the husband and wife felt that the children were standing next to the wife on her side of the wall, but by questioning it appeared as if the children formed an important part of the wall (cf. figure 3).

\section{FIGURE 3: As viewed by the clients}
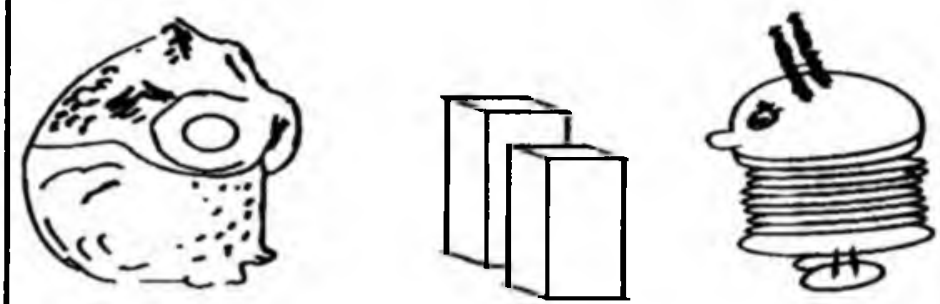

A number of further questions and hypotheses concerning the situation were then generated. Examples of these could be the following: Since 
when had the children assumed the position between them? Which of them had the greatest share in this? What did each of them do to maintain the children's positions? What did each child do to stay in this position? Where did the children fit into the sculpting prior to this situation? Which advantages and disadvantages did the situation hold for each member of the family? What would happen if the children were to move out of the specific positions and did not form a wall anymore? Upon enquiry it seemed as if both marital partners had come to numerous new insights (stories) regarding their marital and family dynamics during the session, and that the sculpting had clearly indicated which structural changes they could bring about in their family relationships.

The third session extended the sculpting pattern to include the role of the husband's job and the wife's family of origin. The husband's job was represented by a small monster, and the members of his wife's family of origin were represented by a number of erasers. During this and later sessions the new themes (stories) raised by the marital partners were incorporated into the sculpting. This obviously led to new sets of questions and hypotheses, and possible ways in which the marital partners could address their problems

Therapy was ceased after seven sessions, as both partners then indicated that there had been an improvement, and that they felt that they were busy removing the wall between them. Information regarding various aspects of their marital and family relationships confirmed their suppositions.

\section{Rationale of the technique}

The rationale underpinning the technique can be formulated as follows:

- The implementation of the technique is a visual spatial metaphor which enables one to redefine complex, and often vague marital issues in a simple, workable form. This representation of a situation creates a new "language" which minimizes the possibility of misinterpretation between the therapist and the marital partners.

- The technique appeals to the functions more specifically associated with the right hemisphere of the brain, i.e. the functions particularly responsible for the holistic, intuitive and creative processes. The discussion revolving around the sculpting process contributes to an integration of the cognitive, affective and experiential components (cf. Wissing, 1991).

- In the application of the technique each partner is intellectually involved in studying material with a high emotional content and thus 
acquires new knowledge about it. The partners can therefore be more objective about marital issues as they get to know themselves better, and can assume the "I" position. This position will promote the partners' self-differentiation within their marriage. This hypothesis rests on Bowen's theoretical assumptions (Bowen, 1976) and the view of Papp et al. (1973) that individuation can be brought about as a result of family sculpting.

- As with family sculpting (Cromwell et al., 1980), the technique discussed in this article has an adhesive effect on marriages. Marital partners realize that they constitute a unit and that each partner is not only an essential part of it, but also influences the other person in the unit.

- Partners become aware of the positive and negative characteristics of their marriage and how this information can enable them to affect certain changes in their relationships with their partners or with others.

- As with sculpting, the active and novel nature of this technique demands more attention than marital discussions, and it is therefore ideally suited to counteract boredom and restlessness, inattention and repetitive, meaningless interchanges (cf. L'Abate et al., 1986).

- Because of the unique nature of the technique, people often find it interesting and not as threatening as one could expect. Humour can also easily be incorporated into the process.

- The sculpting of the marital partners' interaction is a unique way through which they are enabled to externalise their problems. In this process the problems become a separate entity, and thus external to and separate from the persons themselves and the relationship to which the problem was initially ascribed. Because the problem is rendered less fixed, it enables the persons to separate themselves from the dominant stories that have been shaping their lives (cf. White \& Epston, 1990).

- The sculpting helps the therapist not to become too involved or even sucked into the emotional system of the marital partners. This advantage is achieved because the sculpting process creates some distance and it is therefore easier for the therapist to be and to stay cognitively involved in the process (cf. Bowen, 1976).

\section{Conclusion}

Marital couples exposed to this technique/approach can provide important information regarding the impact that the technique has on 
them, and it is therefore imperative that research should be done on marital couples' experience of the technique.

Another aspect that could/should be investigated is how Christian psychologists who use an explicit Biblical approach in their therapeutic conversations could possibly involve the aspects of God's presence and His prescriptions for Christian's marital life in the sculpting process. It goes without saying that such an approach would have to be done very carefully and circumspectly. A possible way of doing this is to see the walls of the therapy room as God's all-embracing and loving presence

\section{Bibliography}

ANDERSEN, T. 1998 Inner and outer voices in the reflecting process Pre-Congress Workshop during the Xth World Family Therapy Congress. Dusseldorf, Germany 14-15 May 1998

ANDERSON, H. \& GOOLISHIAN, H.A 1988. Human systems as linguistic systems: Preliminary and evolving ideas about the implications for clinical theory. Family Process, 27(4):371-393.

BARTLE, SE. \& ROSEN, K. 1994. Individuation and relationship violence. The American Journal of Family Therapy, 22(3) 222-236.

BECVAR, D.S \& BECVAR, R.J. 1996. Family therapy: A systemic integration. Third Edition. Boston : Allyn \& Bacon

BOWEN, M. 1976 Principles and techniques of multiple family therapy. (In Guerin, P J., ed Family therapy: Theory and practice. New York: Gardiner. p. 42-90.)

CECCHIN, G 1987. Hypothesizing, circularity and neutrality revisited: An invitation to curiosity. Family Process, 26(4):405-413

COLAPINTO, J 1991. Structural family therapy. (In Gurman, A.S. \& Kniskern, D.P., eds Handbook of family therapy. Volume II New York: Brunner/Mazel. p. 417443 )

CROMWELL, R., FOURNIER, D \& KVEBAEK, F. 1980. The Kvebaek family sculpture technique: A diagnostic and research tool in family therapy Jonesboro, Tennessee : Pilgrimage.

DASHTI, 1.O. \& WIGG, DS. 1997 . The evolution of family therapy and family therapist: Making the shift from modernism to postmodernism. Paper read at the 7th International Conference on Family Therapy of the Israeli Association for Marital and Family Life Education. (The 9th World Conference on Family Therapy.) Jerusalem, Israel. 9-13 March 1997

DE BRUYN, P.J. 1996. Wesenskenmerke van die huwelik. Bybelse beginsels vir die huwelik. (In Swanepoel, F A, red. Die huwelik. Pretoria : Powell-Bybelsentrum. p. 15-22)

DE SHAZER, S. 1991. Putting difference to work New York: Norton

EVERETT, C.A \& VOLGY, S S 1991 Treating divorce in family therapy practice. (In Gurman, A S \& Kniskern D P., eds. Handbook of family therapy Volume II. New York Brunner/Mazel. p. 508-524.)

GOLDNER, $V$ 1998. The treatment of violence and victimization in intimate relationships. Family Process, 37(3):263-286

HANNA, S M. \& BROWN, JH 1999 The practice of family therapy Key elements across models. Second Edition. London Wadsworth 
HEWSON, D 1991. From laboratory to therapy room: Prediction questions for reconstructing the "new-old" story. Dulwich Centre Newsletter, 3:5-12

HODGES, WF 1991 Interventions for children of divorce: Custody, access and psychoterapy Second Edition. New York: John Wiley.

HOLTZWORTH-MUNROE, A \& JACOBSON, N.S. 1991 Behavioral martial therapy. (In Gurman, A S. \& Kniskern D P, eds Handbook of family therapy. Volume II New York: Brunner/Mazel p 96-133)

KARPEL, M 1976. Individuatıon: From fusion to dialogue Family Process, 15:65-82.

KERR, ME. 1981. Family systems theory and therapy. (In Gurman, A S. \& Kniskern D.P., eds Handbook of family therapy. New York: Brunner/Mazel p 226-264.)

KRUGER, S.F. 2000 Menslike persoonlikheid en toerustende herderlike bediening Aspekte van ' $n$ metateorie, basisteorie en praktykteorie. Unpublished doctoral theses in progress. Potchefstroom : PU vir $\mathrm{CHO}$

L'ABATE, L, GANAHL, G \& HANSEN, J.C. 1986. Methods of family therapy Englewood Cliffs, New Jersey: Prentice-Hall.

LEVANT, RF. 1984. Family therapy: A comprehensive overview. Englewood Cliffs, New Jersey : Prentice-Hall.

MADANES, C. 1991. Strategic family therapy. (In Gurman, AS \& Kniskern, D P., eds Handbook of family therapy. Volume II. New York: Brunner/Mazel p. 417443.)

PAPP, P., SILVERSTEIN, O. \& CARTER, E 1973. Family sculpting in preventive work with "well families". Family Process, 12(2): 197-212

PALAZZOLI, M.S., BOSCOLO, L., CECCHIN, G. \& PRATA, G. 1980. Hypothesizing - circularity - neutrality: Three guidelines for the conductor of the session. Family Process, 19(1):3-11

SAGER, C.J 1981. Couples therapy and marriage contracts. (In Gurman, AS \& Kniskern, D.P., eds. Handbook of family therapy. New York: Brunner/Mazel. p 85-130.)

STATISTICS SOUTH AFRICA. 1998. Marriages and divorces: Statistical release, P0307.

VENTER, C.A., VAN DER BERG, A.M., VAN DER MERWE, H.J. \& VAN RENSBURG, E. 1995. Psychological team approach to child custody and access disputes. The Social Work Practitioner - Researcher, 9(2):106-115.

WISSING, M.P 1991 Differentiation and integration: Congruence between qualities of personality and neuropsychological functioning Paper read at Second International Conference on Client Centered and Experiential Psychotherapy: Theory, Research and Practice. Stirling, Scotland. 1-6 July 1991

WHITE, M. 1991. Deconstruction and therapy. Dulwich Centre Newsletter, 3:21-40

WHITE, M. 1995. Re-authoring lives: Interviews and essays Adelaide : Dulwich Centre Publictions.

WHITE, M \& EPSTON, D 1990. Narrative means to therapeutic ends. New York WW. Norton.

WORDEN, M. 1999. Family therapy basics. Second Edition. Pacific Grove : Brooks/ Cole.

Key concepts:

co-therapists

maritial therapy

narrative therapy

sculpting

\author{
Kernbegrippe: \\ beelding \\ huweliksterapie \\ ko-terapeute \\ narratiewe terapie
}

